\title{
Absence of death receptor translocation into lipid rafts in acquired TRAIL-resistant NSCLC cells
}

\author{
WEN OUYANG ${ }^{1}$, CHUNXU YANG $^{1}$, SIMIN ZHANG $^{1}$, YU LIU $^{1}$, BO YANG ${ }^{1}$, JUNHONG ZHANG $^{1}$, \\ FUXIANG ZHOU ${ }^{1}$, YUNFENG ZHOU ${ }^{1,2^{*}}$ and CONGHUA XIE ${ }^{1,2^{*}}$ \\ ${ }^{1}$ Department of Radiation and Medical Oncology, ${ }^{2}$ Hubei Key Laboratory of Tumor Biological Behaviors, \\ Zhongnan Hospital, Wuhan University, Wuhan 430071, P.R. China
}

Received October 6, 2012; Accepted November 30, 2012

DOI: $10.3892 /$ ijo.2012.1748

\begin{abstract}
Resistance to tumor necrosis factor-related apoptosis-inducing ligand (TRAIL) is a major limitation for its clinical use. The mechanisms of TRAIL resistance have been mostly studied in the context of cell lines that are intrinsically resistant to TRAIL. However, little is known about the molecular alterations that contribute to the development of acquired resistance during treatment with TRAIL. In this study, we established H460R, an isogenic cell line with acquired TRAIL resistance, from the TRAIL-sensitive human lung cancer cell line H460 to investigate the mechanisms of acquired resistance. The acquired TRAIL-resistant H460R cells remained sensitive to cisplatin. The mRNA and protein expression levels of death receptor 4 (DR4) and death receptor 5 (DR5) were not altered in either of the TRAILtreated cell lines. Nevertheless, tests in which the DR4 or DR5 gene was overexpressed or silenced suggest that death receptor expression is necessary but not sufficient for TRAIL-induced apoptosis. Compared with parental TRAIL-sensitive H460 cells, H460R cells showed a decreased TRAIL-induced translocation of DR4/DR5 into lipid rafts. Further studies showed that nystatin partially prevented lipid raft aggregation and DR4 and DR5 clustering and reduced apoptosis in H460 cells again. Analysis of apoptotic molecules showed that more pro-caspase-8, FADD, caspase- 3 and Bid, but less cFLIP in H460 cells than in H460R cells. Our findings suggest that the lack of death receptor redistribution negatively impacts DISC assembly in lipid rafts, which at least partially leads to the development of acquired resistance to TRAIL in H460R cells.
\end{abstract}

Correspondence to: Dr Conghua Xie, Department of Radiation and Medical Oncology, Zhongnan Hospital, Wuhan University, 169 Donghu Road, Wuchang District, Wuhan 430071, P.R. China E-mail: chxie_65@hotmail.com

*Joint senior authorship

Key words: tumor necrosis factor-related apoptosis-inducing ligand, acquired resistance, death receptor, redistribution, lipid rafts

\section{Introduction}

Tumor necrosis factor (TNF)-related apoptosis-inducing ligand (TRAIL) is a member of the TNF family $(1,2)$. Recombinant TRAIL (rhTRAIL) and its agonist antibodies are capable of inducing apoptosis in human cancer cells and sparing most normal human cells $(3,4)$ and are, therefore, currently under clinical trials as therapeutic agents for human cancers $(3,5)$. TRAIL-induced apoptosis is mediated by the transmembrane receptor death receptor 4 (DR4) (TRAIL-R1) (6) and DR5 (TRAIL-R2) (7) located on the target cell surface. Each receptor contains a cytoplasmic region designated the "death domain' responsible for transducing the death signal. On ligand binding, DR4 or DR5 initiates apoptosis by assembling death induced signaling complex (DISC) components at the inner surface of the plasma membrane (8). This is achieved by their death domains recruiting the adaptor molecule Fas-associated death domain (FADD) and the apoptosis initiating protease pro-caspase- 8 (or pro-caspase-10). Within the DISC, pro-caspase- 8 or pro-caspase- 10 is autocatalytically cleaved and in turn, subsequently cleaves and activates effector caspases, such as caspase- 3 , caspase- 6 and caspase-7 in an extrinsic apoptotic pathway. At the same time, caspase- 8 stimulates the cleavage of Bid, thus amplifying caspase activation via mitochondrial activation of the intrinsic apoptotic pathway (9).

TRAIL has been shown to induce apoptosis of lung cancer cell lines, but recent studies have shown that some cancer cells, including lung cancer cells, can acquire resistance during TRAIL treatment (10-13). Patients with tumors which acquire TRAIL-resistance during treatment probably suffer from the potential side-effects rather than benefit from TRAIL treatment. Up to now, little is known about the molecular mechanisms that contribute to the development of acquired resistance during treatment with TRAIL. Consequently, understanding acquired TRAIL-resistance may enable us to design better strategies to prevent its occurrence and to improve the therapeutic potential of TRAIL. So far, intrinsic TRAIL-resistance has been attributed to the loss of TRAIL death receptors, upregulation of TRAIL decoy receptors, downregulation of caspase- 8 or caspase-10, enhanced expression of cellular FLICE-like inhibitory protein (cFLIP) and cIAP or alterations in expression of the Bcl-2 family 
proteins $(14,15)$. However, none of these factors show a consistent correlation with acquired TRAIL resistance in multiple cancer cells.

For TRAIL-induced apoptosis, TRAIL binding to its death receptors is an upstream event during caspase activation and the receptors are crucial in initialing apoptosis. Accordingly, downregulation of TRAIL death receptors and upregulation of TRAIL decoy receptors both lead to TRAIL-resistance, also confirmed by a previous study (17). However, there seems to be no evidence of a direct correlation between the expression level of a receptor and the sensitivity of cancer cells to TRAIL $(3,18)$. Recent studies suggest that mRNA and protein expression levels of death receptors do not reflect their functional protein levels due to post-translational regulation (16). Moreover, other studies indicate that the functional status of death receptors correlates with the death receptor expression levels on the cell surface in some colon cancer cells (19) and leukemia cells (20).

Lipid rafts are plasma membrane microdomains enriched in cholesterol and glycosphingolipids (21). They have an important role in clustering or aggregating surface receptors into membrane complexes at specific sites and this is essential for initiating signaling from several receptors $(11,22,23)$. Several studies report that the distribution of receptors in lipid rafts is related to their sensitivity to their respective ligands (24). Drugs or interventions that can interact with lipid rafts are capable of affecting the sensitivity to TRAIL by altering receptor distribution in the plasma membrane (25). Consequently, death receptor distribution in lipid rafts might play an important role in the development of acquired TRAIL-resistance of cancer cells. In this study, we established the isogenic TRAIL-resistant cell line H460R from the TRAIL-sensitive human lung cancer cell line H460 to examine the potential mechanisms of acquired resistance to TRAIL.

\section{Materials and methods}

Cell culture and acquired TRAIL-resistant lung cancer cell line. The human non-small cell lung carcinoma (NSCLC) cell line NCI-H460 (H460) was obtained directly from the Type Culture Collection of the Chinese Academy of Sciences (Shanghai, China), where cell lines have been tested and authenticated, and the H460 cell line was passaged in our laboratory for less than 6 months after resuscitation. The cells were cultured in RPMI-1640 medium (HyClone, Logan, UT, USA) containing $10 \%$ heat-inactivated fetal bovine serum (FBS), penicillin $(100 \mathrm{U} / \mathrm{ml})$ and streptomycin $(100 \mathrm{mg} / \mathrm{ml})$ at $37^{\circ} \mathrm{C}$ in a humidified atmosphere of $5 \% \mathrm{CO}_{2}$.

To establish an acquired TRAIL-resistant lung cancer cell line, parental H460 cells were plated at clonal density in 24-well plates to ensure there was no more than one cell in each well. H460 is a TRAIL-sensitive sub-line which is lethal under $80 \mathrm{ng} / \mathrm{ml}$ rhTRAIL treatment and it was exposed to stepwise increases in rhTRAIL concentrations $(10-128 \mathrm{ng} / \mathrm{ml})$ over a period of 2 months to induce cells capable of growing at high concentrations of rhTRAIL. The resulting cell line was designated as H460R. H460R cells were cultured in medium with continuous exposure to $50 \mathrm{ng} / \mathrm{ml} \mathrm{rhTRAIL}$ to maintain their TRAIL resistance.
Antibodies and reagents. rhTRAIL, designed for clinical use, was obtained from Shanghai Bio-Tech Co. Ltd. (Shanghai, China). Monoclonal antibodies to human DR4 and DR5, and caspase-3, and caspase-8 were purchased from Abcam. Antibodies to caveolin-1, FADD, Bid, cFLIP and GAPDH were from Santa Cruz Biotechnology. Fluorescein (FITC)-conjugated goat anti-mouse/rabbit IgG and rhodamine (TRITC)-conjugated goat anti-rabbit IgG were from Jackson ImmunoResearch Laboratories. Horseradish peroxidase (HRP)-conjugated goat anti-mouse IgG and goat anti-rabbit IgG were from Southern Biotech. The broad-spectrum caspase inhibitor ZVAD-fmk, nystatin, Triton X-100, Tween-20 and other chemicals of analytical grade were purchased from Sigma-Aldrich (Oakville, ON, Canada).

Plasmids, siRNA and transfection. For plasmid construction, DR4/DR5 cDNA was amplified from the total-mRNA of H460 cells by RT-PCR and was subcloned into pRetroQ-DsRed Monomer-C1 vectors/pEGFP-C1 vectors (Clontech Laboratories, Mountain View, CA, USA), yielding a construct for expression of a fusion protein with a DsRed-monomer/GFP tag at the C-terminus of DR4/DR5. All constructs were verified by automated DNA sequencing.

For small interfering RNA (siRNA) oligonucleotides, DR4, DR5 and negative control FAM siRNA oligonucleotides were obtained from Shanghai GenePharma Co. Ltd. (Shanghai, China). Three pairs of siRNA oligonucleotides each were designed for DR4 and DR5. The negative control FAM siRNA with green fluorescence was used as a control.

For transfection, cells were seeded into 6-well plates without antibiotics. After $24 \mathrm{~h}$, transfections were carried out using the Lipo2000 reagent (Invitrogen, Carlsbad, CA, USA) according to the manufacturer's instructions. The efficiency of transfection was evaluated by fluorescence intensity using inverted fluorescence microscopy (Nikon, Japan).

Cytotoxicity assays. Cytotoxicity and cell survival were determined by the cell counting kit- 8 (CCK-8) assay. Briefly, cells were plated at 20,000 per well in 96-well plates (Corning Inc., Corning, NY, USA). The next day, cells (confluence 80-90\%) were treated with indicated concentrations of rhTRAIL or cisplain and incubated for $4 \mathrm{~h}$. In some experiments, cells were transfected with DR4/DR5 plasmid/siRNA before adding rhTRAIL. At the end of the experiment, the culture medium was removed and a mixture of fresh medium (without phenol red) containing CCK-8 (Sigma-Aldrich) was added for $1 \mathrm{~h}$. The absorbance was determined using a microplate reader at $450 \mathrm{~nm}$ (Tecan, Port Melbourne, VIC, Australia). Cell viability was defined as the relative absorbance of treated versus untreated cells. All assays were performed in five replicates and repeated at least three times.

Apoptosis assays. Cells were grown on 6-well plates to 70-80\% confluence and treated with transfection and/or indicated concentrations of rhTRAIL. First, cells were pretreated with the caspase inhibitor ZVAD-fmk for $2 \mathrm{~h}$ to block endogenous TRAIL-induced apoptosis, then at selected time points, cells were collected and incubated with $5 \mu$ l Annexin V-FTIC (BestBio, Shanghai, China) for $15 \mathrm{~min}$ and $10 \mu \mathrm{l}$ propidium iodide (BestBio) for $5 \mathrm{~min}$ in the dark at $4^{\circ} \mathrm{C}$. The apoptotic 
profile was obtained by flow cytometry immediately afterwards (Beckman Coulter, Miami, FL, USA).

Immunofluorescence flow cytometry. The cell-surface expression of death receptors was analyzed by flow cytometry. First, cells were pretreated with ZVAD-fmk to block TRAIL-induced apoptosis and then cells were treated with $50 \mathrm{ng} / \mathrm{ml}$ rhTRAIL for the time indicated. Cells were harvested and incubated with unlabeled primary antibodies (dilution ratio 1:100) for $1 \mathrm{~h}$ at $4^{\circ} \mathrm{C}$. The respective binding sites of rhTRAIL and primary antibodies to DR4/DR5 are different, which obviates the undetectability of TRAIL-occupied DR4/DR5. After three washes with PBS, cells were incubated with FITC-conjugated goat antirabbit $\mathrm{IgG}$ antibody (dilution ratio 1:50) for $45 \mathrm{~min}$ in the dark at $4^{\circ} \mathrm{C}$. An isotype-matched FITC-conjugated non-relevant IgG monoclonal antibody was used as a negative control, leading to virtually identical background values. Finally, cells were resuspended in $1 \%$ paraformaldehyde in PBS for flow cytometric analysis and both the percentage of antigen-positive cells and the mean fluorescence intensity were measured.

Reverse transcription-PCR. RNA was isolated using the TRIzol reagent (Invitrogen). RT-PCR was carried out using the highfidelity RT-PCR kit (Invitrogen) as per the manufacturer's instructions. Primer pairs used for detection of DR4 are 5'-agaga gaagtccetgcacca-3' and 5'-gtcactccagggcgtacaat-3' $\left(57^{\circ} \mathrm{C}\right)$, primer pairs for DR5 are 5'-caccaggtgtgattcaggtg-3' and 5'-ccccactgtg ctttgtacct-3' $\left(61^{\circ} \mathrm{C}\right)$, primer pairs for GAPDH are 5'-tggaaggact catgaccaca- $3^{\prime}$ and $5^{\prime}$-ttcagctcagggatgacc $\mathrm{tt}-3^{\prime}\left(56^{\circ} \mathrm{C}\right)$. Amplification products were electrophoresed on $1.8 \%$ agarose gels containing ethidium bromide for visualization under UV light. All PCR reactions were performed at least three times. PCR products were normalized to GAPDH expression.

Western blot analysis. Whole-cell extracts were prepared in RIPA lysis buffer (Biyuntian, Shanghai, China) containing protease inhibitors and were separated by 10-12\% SDS-PAGE electrophoresis under denaturing conditions, then transferred to PVDF membranes by electroblotting. The membrane was blocked with 5\% skim milk in TBST buffer, incubated with the primary antibodies and reacted with HRP-conjugated secondary antibodies. The immunoreactive proteins were visualized with chemiluminescence reagent (Biyuntian). GAPDH was used to normalize protein levels.

Confocal microscopy. Cells were cultured on glass chamber slides to 50-60\% confluence and treated with rhTRAIL and/or nystatin. First, cells were fixed with 4\% PBS-buffered paraformaldehyde for $20 \mathrm{~min}$, washed with PBS three times, and blocked with $1 \%$ goat serum for $1 \mathrm{~h}$. Afterwards, cells were counterstained with DR4/DR5 rabbit monoclonal antibody and caveolin- 1 mouse monoclonal antibody at $4{ }^{\circ} \mathrm{C}$ overnight, then counterstained with TRITC-conjugated goat anti-rabbit antibody and FITC-conjugated goat anti-mouse antibody at room temperature in the dark for $1 \mathrm{~h}$. Immunofluorescence was analyzed using a confocal laser-scanning microscope (Leica, Wetzlar, Germany). The respective binding sites of rhTRAIL and primary antibodies to DR4/DR5 are different, which obviates the undetectability of TRAIL-occupied DR4/ DR5.
Lipid raft and non-raft isolation. Lipid raft and non-raft-soluble fractions were separated by discontinuous sucrose density gradients of Triton X-100 cell lysates from treated and untreated cells. Briefly, cells from 10 flasks of $15 \mathrm{~cm}$ culture dishes $\left(1 \times 10^{8}\right.$ cells) were homogenized on ice for $30 \mathrm{~min}$ in $1 \mathrm{ml}$ of MNX buffer (1\% Triton X-100 in $25 \mathrm{mmol} / \mathrm{l} \mathrm{MES}$, $150 \mathrm{mmol} / \mathrm{l} \mathrm{NaCl}, \mathrm{pH} 6.5$ ) supplemented with $1 \mathrm{mmol} / \mathrm{l}$ of phenylmethylsulfonyl fluoride and protease inhibitor cocktail. The homogenates were mixed with $1 \mathrm{ml}$ of $80 \%$ sucrose made with MNX buffer and placed on the bottom of a centrifuge tube. The samples were then overlaid with $3.5 \mathrm{ml}$ of $35 \%$ sucrose and $3.5 \mathrm{ml}$ of $5 \%$ sucrose and centrifuged at 175,000 x g (Beckman Coulter) for $20 \mathrm{~h}$ at $4^{\circ} \mathrm{C}$. Nine fractions $(1 \mathrm{ml})$ were collected from the top to the bottom of the gradient and analyzed. To identify lipid raft fractions, the fractions were examined by western blot analysis with antibody to the lipid rafts marker caveolin-1 (26). The protein in each fraction was analyzed by western blot analysis.

\section{Results}

Characterization of TRAIL-resistant cells. To examine the molecular alterations that can lead to acquired TRAIL-resistance, we developed an isogenic TRAIL-resistant H460R cell line from a TRAIL-sensitive parental H460 cell line. At a TRAIL concentration of $50 \mathrm{ng} / \mathrm{ml}$, some H460 cells were rounded and floating in the medium, suggesting cell death, whereas H460R cells formed a typical epithelioid monolayer (Fig. 1A). The ability of TRAIL induced cell death was determined by measuring the percentage of viable cells using a CCK-8 assay. The CCK-8 assay confirmed that H460 cells $\left(\mathrm{IC}_{50}=50 \mathrm{ng} / \mathrm{ml}\right)$ were TRAIL sensitive, whereas H460R cells $\left(\mathrm{IC}_{50}=250 \mathrm{ng} / \mathrm{ml}\right)$ were TRAIL resistant (Fig. 1B). Consistent with these results, flow cytometric analysis showed that H460 cells exhibited a higher apoptotic rate after rhTRAIL treatment (Fig. 1C and D). To assess whether H460R cells were cross-resistant to cytotoxic drugs, such as cisplatin, they and the parental H460 cells were exposed to increasing concentrations of cisplatin and cell survival was determined by the CKK-8 assay. We found that both TRAIL-resistant cells and TRAIL-sensitive cells were efficiently killed by the drug (Fig. 1E). Less than $20 \%$ cell survival was observed at high concentrations of cisplatin. Flow cytometric analysis of apoptosis in H460 and H460R cells indicated that both cell lines were similarly susceptible to cisplatin (data not shown). The data show that TRAIL-resistant H460R cells remained sensitive to cytotoxic drugs. This is significant for the management of platinum-based chemotherapeutic regimens.

Expression of death receptors is not altered in H460R cells. TRAIL-induced apoptosis occurs through its binding to receptors DR4 and DR5 (27). The receptors are crucial in initialing apoptosis. The expression of DR4 and DR5 was evaluated by RT-PCR (Fig. 2A) and western blot analysis (Fig. 2B). We did not observe any marked distinction between DR4/DR5 expression in H460R cells and H460 cells, even when cells were pretreated with $50 \mathrm{ng} / \mathrm{ml} \mathrm{rhTRAIL}$ for $2 \mathrm{~h}$. Our results confirm that there is no correlation between the mRNA and protein expression levels of death receptors and sensitivity to TRAIL. 
A
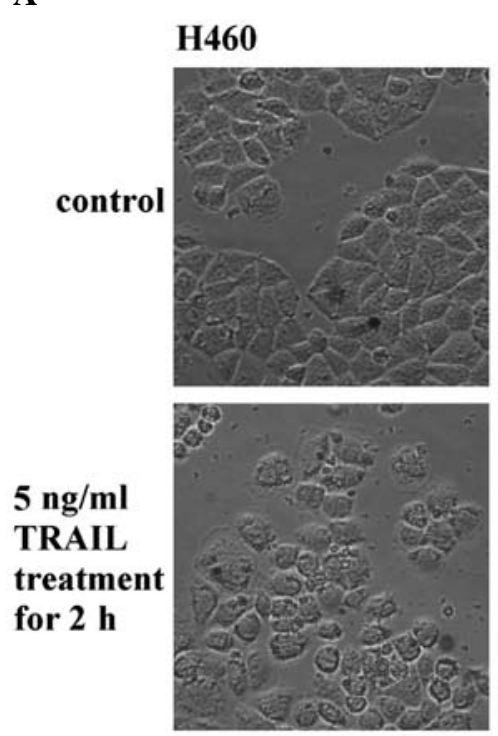

\section{H460R}
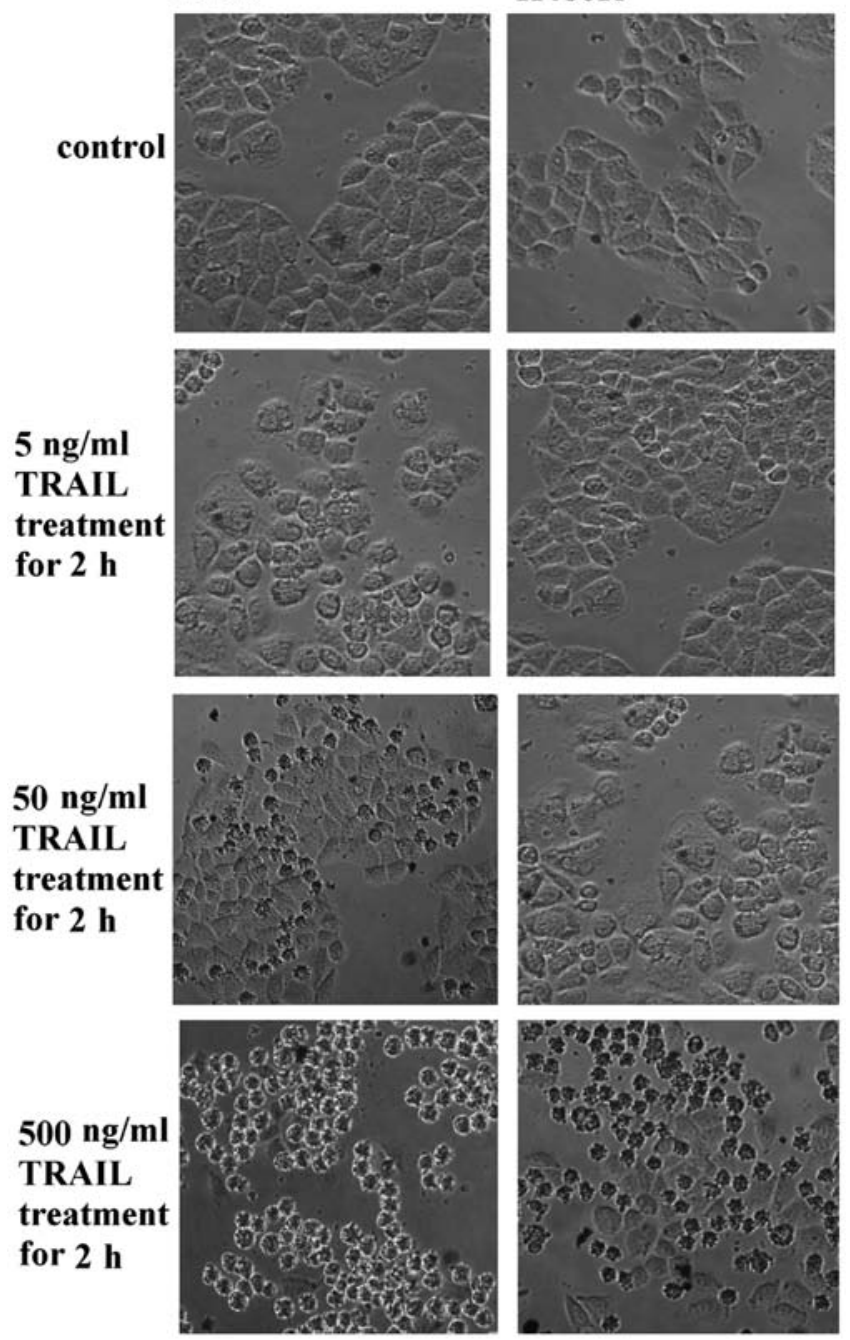

B

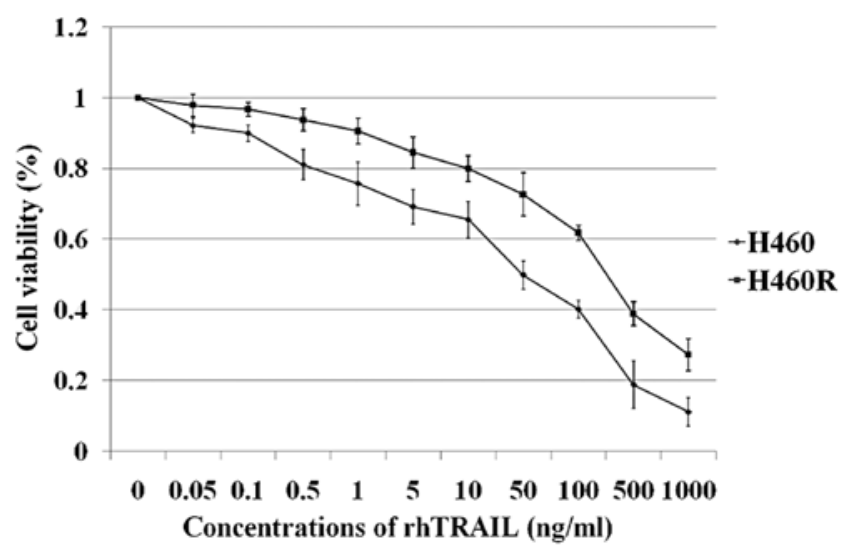

C

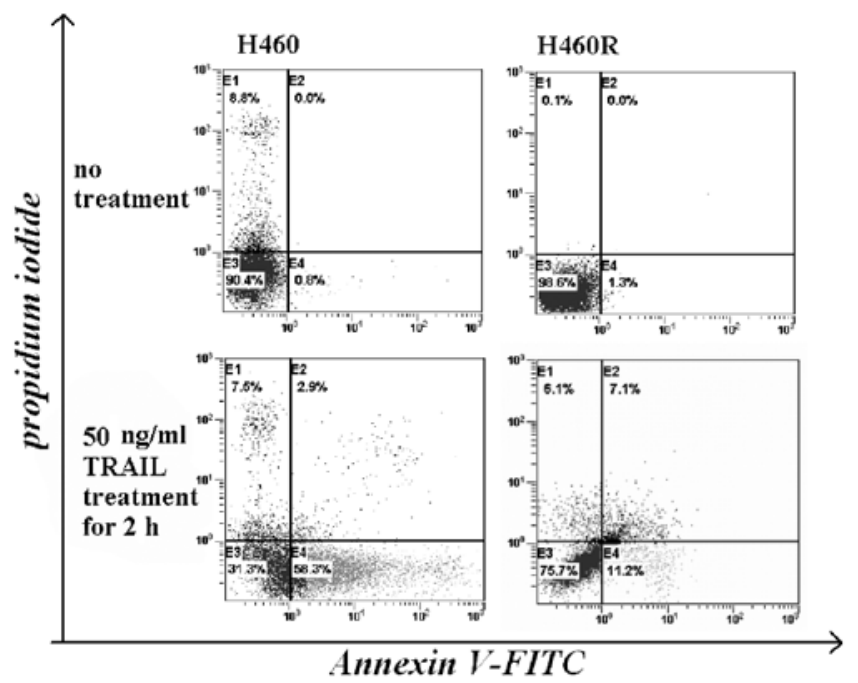

D

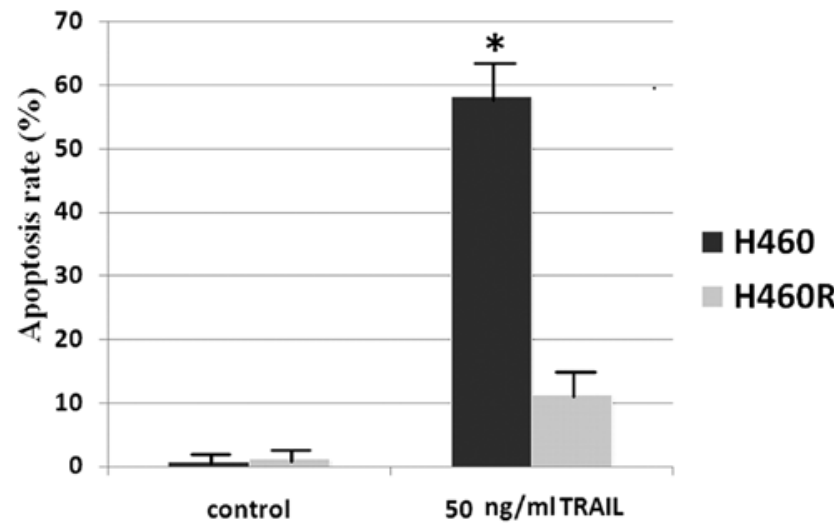

$\mathbf{E}$

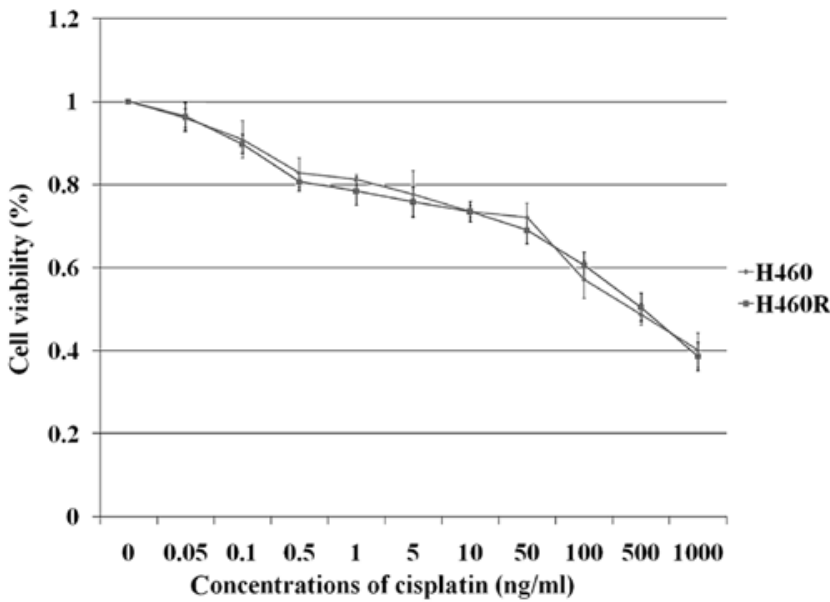

Figure 1. Characterization of TRAIL-resistant cells. (A) Morphologic analysis of parental H460 cells and acquired TRAIL-resistant H460R cells treated with the indicated concentrations of rhTRAIL. The actual magnification of all photomicrographs is $\mathrm{x} 200$. (B) H460/H460R cells exposed to medium containing rhTRAIL from 0 to $1,000 \mathrm{ng} / \mathrm{ml}$ for $4 \mathrm{~h}$ were tested using the CCK-8 assay to determine cell viability. All assays were performed in five replicates and repeated at least three times. The result is shown as a line graph (mean $\pm \mathrm{SD}$ ). The abscissa axis indicates concentrations of rhTRAIL (ng/ml), and the longitudinal axis indicates cell viability (\%). (C) H460/H460R cells exposed to medium containing $0 \mathrm{or} 50 \mathrm{ng} / \mathrm{ml}$ rhTRAIL for $2 \mathrm{~h}$ were analyzed by flow cytometry after staining with Annexin V-FITC and propidium iodide for apoptosis. At first, cells were pretreated with the caspase inhibitor ZVAD-fmk for $2 \mathrm{~h}$ to block endogenous TRAIL-induced apoptosis. (D) A graphical representation of the mean ( \pm SD) data presented in (C). All assays were repeated at least three times. Columns, data; bar, SD; "P<0.05 compared with control. (E) H460/H460R cells exposed to medium containing cisplain from 0 to $1,000 \mathrm{ng} / \mathrm{ml}$ for $4 \mathrm{~h}$ were tested by CCK-8 assay to determine cell viability. All assays were performed in five replicates and repeated at least three times. The result was shown as line graph (mean \pm SD). The abscissa axis indicates concentrations of cisplain $(\mathrm{ng} / \mathrm{ml})$ and the longitudinal axis indicates cell viability $(\%)$. 
A

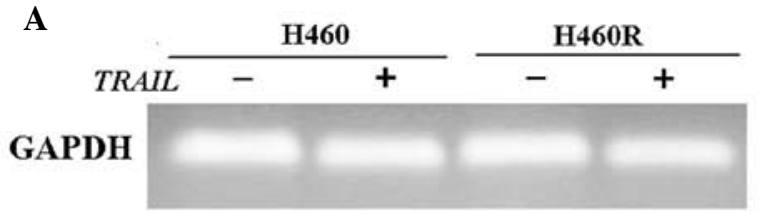

DR4

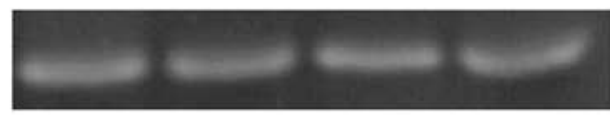

DR5

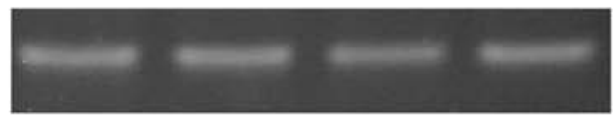

B

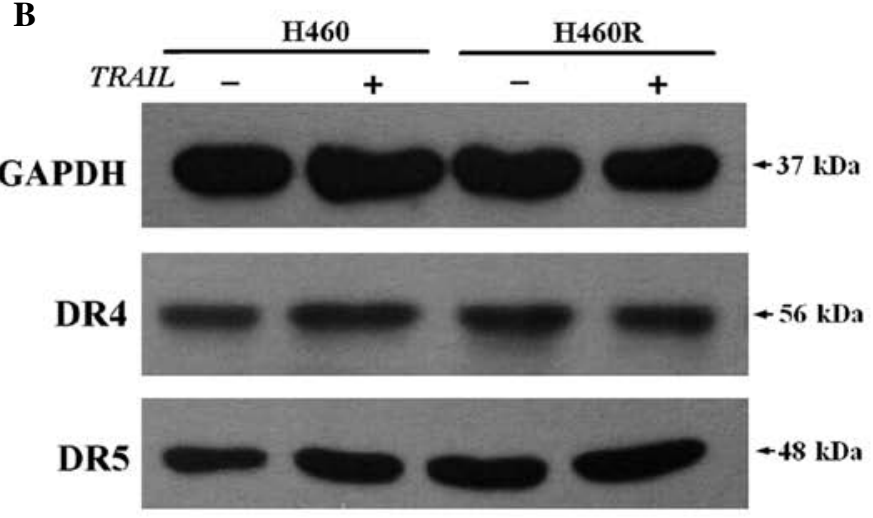

Figure 2. The death receptor expression levels of parental TRAIL-sensitive H460 cells and acquired TRAIL-resistant H460R cells. (A) The mRNA expression of DR4/DR5 in H460 and H460R cells was detected by RT-PCR. (B) The protein expression of DR4/DR5 from H460 and H460R cells was detected by western blot analysis. The mRNA/protein expression of DR4/DR5 was normalized with GAPDH.
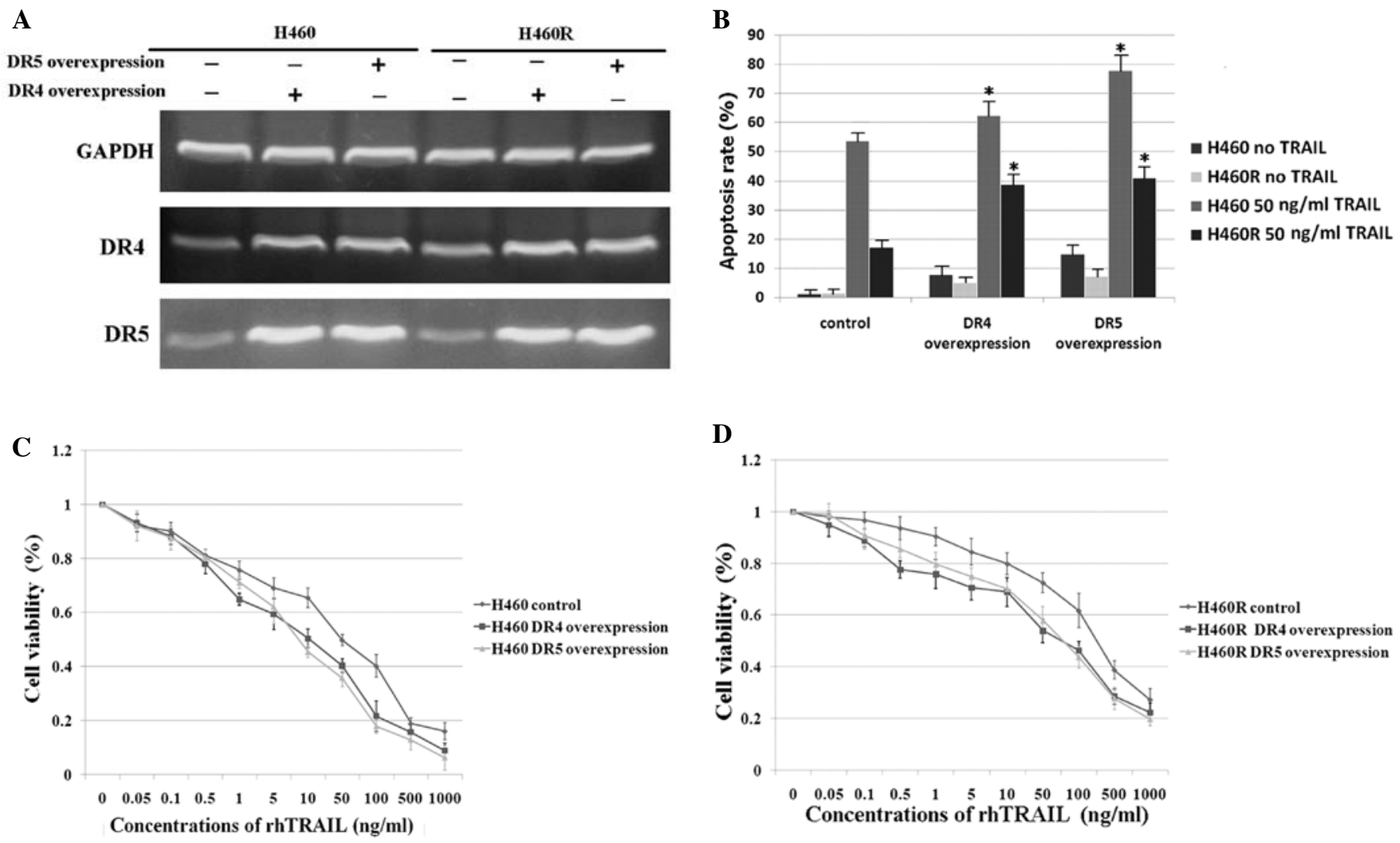

Figure 3. Apoptosis and viability of H460/H460R cells with or without death receptor gene overexpression. (A) The mRNA expression of DR4/DR5 in H460/H460R cells with or without DR4/DR5 gene overexpression was examined by RT-PCR. (B) The apoptotic rate of H460/H460R cells with or without DR4/DR5 gene overexpression was analyzed by flow cytometry after 0 or $50 \mathrm{ng} / \mathrm{ml}$ rhTRAIL treatment for $2 \mathrm{~h}$. At first, cells were pretreated with the caspase inhibitor ZVAD-fmk for $2 \mathrm{~h}$ to block endogenous TRAIL-induced apoptosis. All assays were repeated at least three times. The result was shown as histogram (mean \pm SD). Columns, data; bar, S.D.; "P<0.05 compared with control. (C) The viability of H460 cells with or without DR4/DR5 gene overexpression after rhTRAIL treatment at indicated concentrations for $4 \mathrm{~h}$, tested by CCK-8 assay. (D) The viability of H460R cells with or without DR4/DR5 gene overexpression after rhTRAIL treatment at indicated concentrations for $4 \mathrm{~h}$, tested by CCK- 8 assay. All assays were performed in five replicates and repeated at least three times. The result was shown as line graph (mean $\pm \mathrm{SD}$ ). The abscissa axis indicates concentrations of rhTRAIL $(\mathrm{ng} / \mathrm{ml})$ and the longitudinal axis indicates cell viability $(\%)$.

Overexpression of death receptors upregulates sensitivity to TRAIL. To further explore the role of death receptors in TRAIL-induced apoptosis, overexpression of DR4/DR5 was performed in the parental $\mathrm{H} 460$ cells and the acquired TRAIL-resistant H460R cells. After transfection with a
DR4/DR5 overexpression plasmid, the expression of DR4/DR5 markedly increased as detected by RT-PCR (Fig. 3A) and this was also confirmed by western blot analysis (data not shown). Moreover, we found that overexpression of DR4 also elevated mRNA expression of DR5 and vice versa (Fig. 3A). This has not 
A
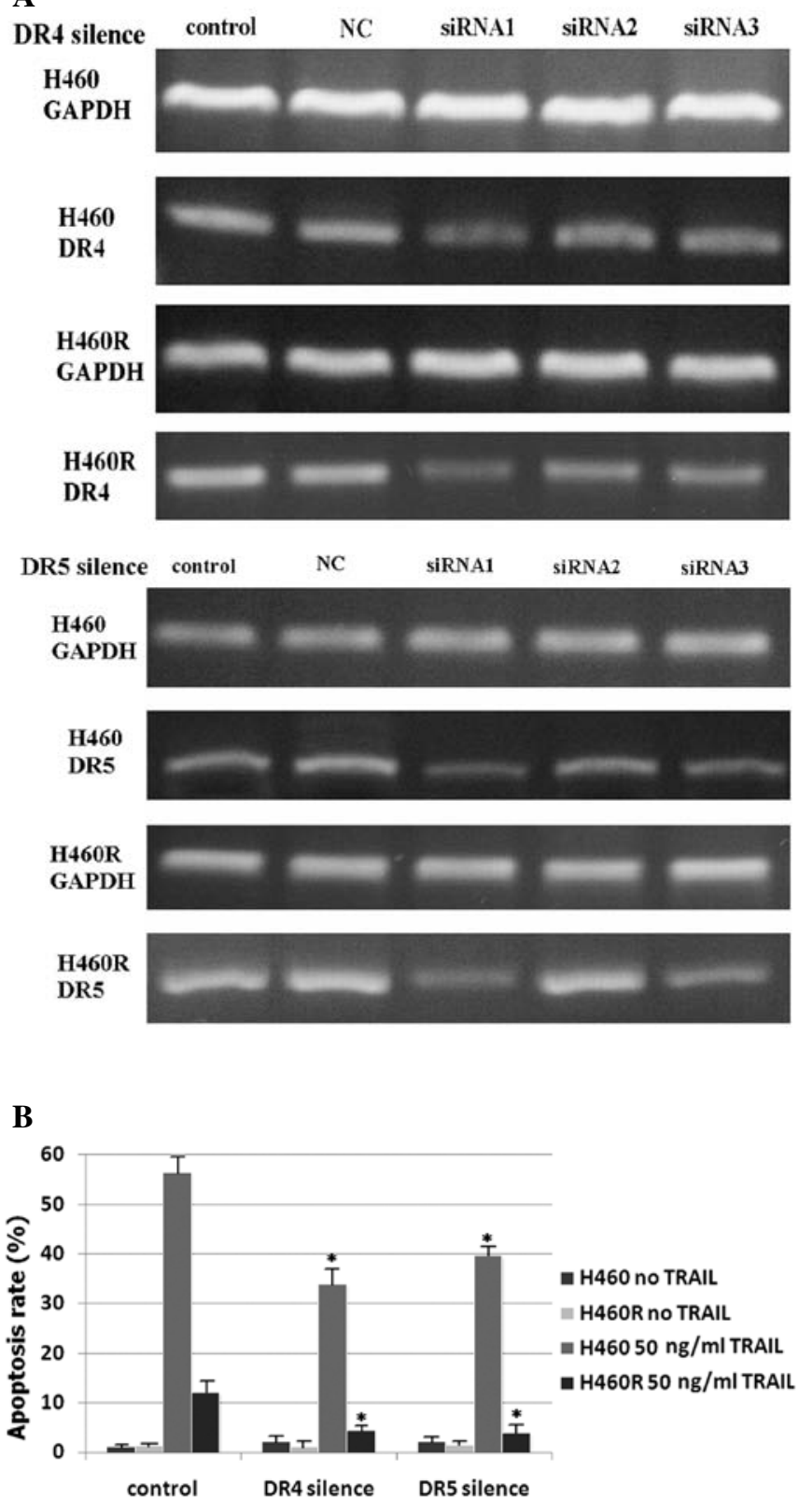

been previously reported and is worthy of further investigation. DR4/DR5 overexpression in H460 and H460R cells significantly elevated TRAIL induced-apoptosis (Fig. 3B) and the CKK-8 assay further showed that the overexpression of death receptors could overcome the acquired TRAIL-resistance of H460R cells (Fig. 3D). Interestingly, equivalent overexpression levels of death receptors led to a higher apoptosis in H460 cells than H460R cells, which also indicated that the expression levels of death receptor mRNA and protein did not directly correlate with their functionality.

Silencing of death receptors downregulates sensitivity to TRAIL. Silencing of DR4/DR5 was performed in parental H460 cells and acquired TRAIL-resistant H460R cells. After DR4/DR5 siRNA (three siRNA oligonucleotides each for DR4 and DR5) transfection, the expression of DR4/DR5 significantly reduced as detected by RT-PCR (Fig. 4A).
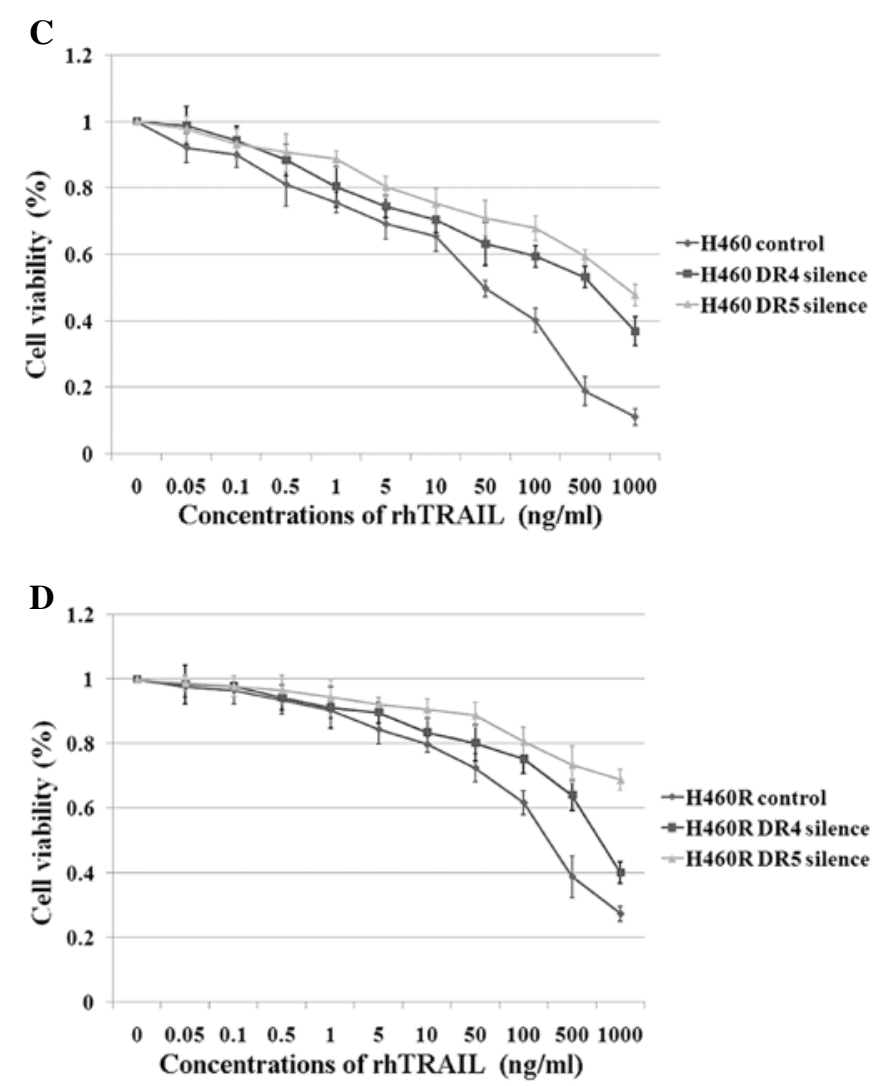

Figure 4. Apoptosis and viability of H460/H460R cells with or without death receptor gene silencing. (A) The mRNA expression of DR4/DR5 in H460/H460R cells with or without DR4/DR5 gene silencing was examined by RT-PCR. (B) The apoptotic rate of H460/H460R cells with or without DR4/DR5 gene silencing was analyzed by flow cytometry after 0 or $50 \mathrm{ng} / \mathrm{ml}$ rhTRAIL treatment for $2 \mathrm{~h}$. At first, cells were pretreated with the caspase inhibitor ZVAD-fmk for $2 \mathrm{~h}$ to block endogenous TRAIL-induced apoptosis. All assays were repeated at least three times. The result was shown as histogram (mean $\pm \mathrm{SD}$ ). Columns, data; bar, $\mathrm{SD} ;{ }^{*} \mathrm{P}<0.05$ compared with control. (C) The viability of $\mathrm{H} 460$ cells with or without DR4/DR5 gene silencing after rhTRAIL treatment at indicated concentrations for $4 \mathrm{~h}$, tested by CCK- 8 assay. (D) The viability of H460R cells with or without DR4/DR5 gene silencing after rhTRAIL treatment at indicated concentrations for $4 \mathrm{~h}$, tested by CCK- 8 assay. All assays were performed in five replicates and repeated at least three times. The result was shown as line graph (mean $\pm \mathrm{SD})$. The abscissa axis indicates concentrations of rhTRAIL $(\mathrm{ng} / \mathrm{ml})$ and the longitudinal axis indicates cell viability $(\%)$.

DR4-siRNA1 and DR5-siRNA1 showed the highest efficiency of gene silencing and consequently all further experiments were conducted with DR4-siRNA1 and DR5-siRNA1. The silencing of death receptors led to resistance to TRAIL, which was shown by detection of apoptosis by flow cytometry (Fig. 4B) and viability by CCK-8 (Fig. 4C and D). These results suggest that the expression of DR4 and DR5 still plays an important role in TRAIL-induced apoptosis.

TRAIL-induced death receptor accumulation on the cell surface. It has been reported that the functional status of death receptors may correlate with the death receptors expression levels on the cell surface in cancer cells (19). We examined the cell surface expression levels of death receptors by flow cytometry using FITC-conjugated antibodies. Nevertheless, H460 and H460R cells showed similar cell surface expression levels of DR4/DR5 (Fig. 5), which confirms that there 
$\mathbf{A}$
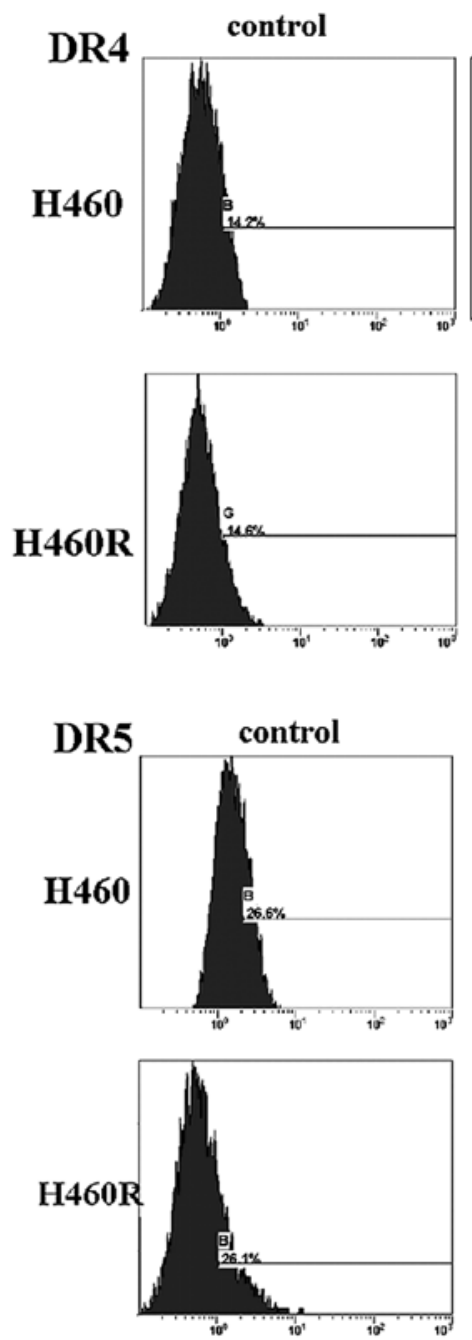

TRAIL $10 \mathrm{~min}$
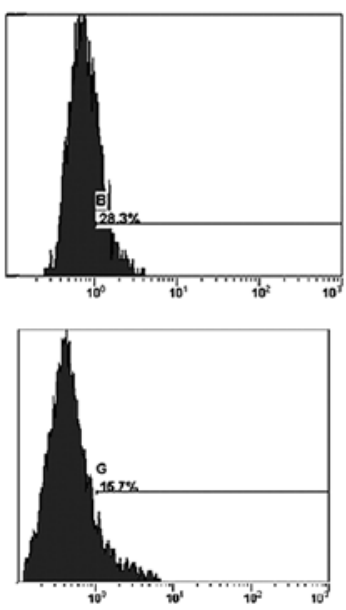

TRAIL $10 \mathrm{~min}$
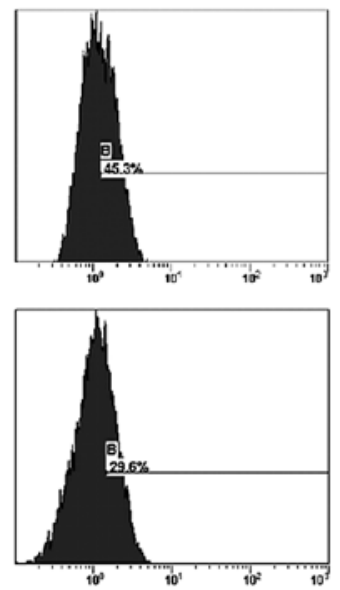

TRAIL 20 min
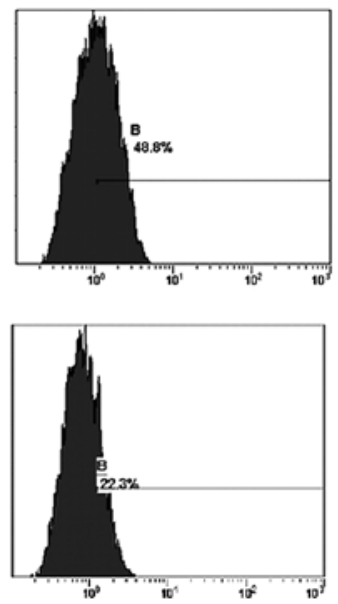

TRAIL $20 \mathrm{~min}$
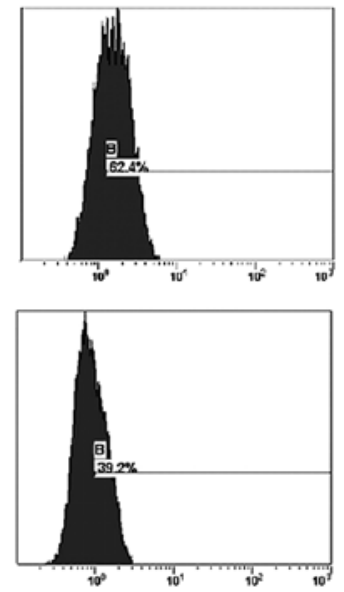

B

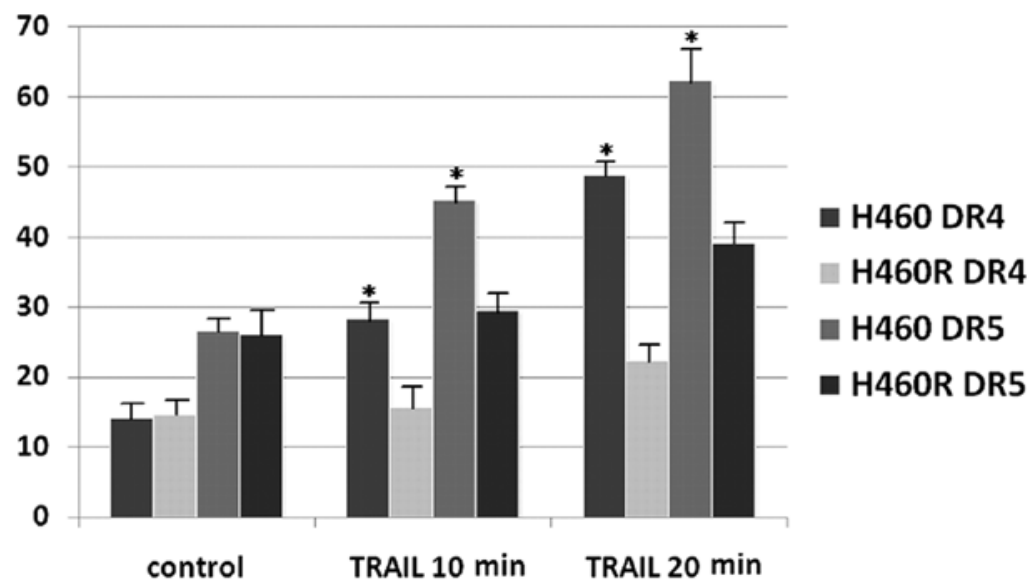

Figure 5. The cell surface death receptor expression levels of H460 and H460R cells with or without TRAIL pretreatment. (A) The cell surface expression levels of DR4 and DR5 on H460/H460R cells with or without $50 \mathrm{ng} / \mathrm{ml}$ rhTRAIL pretreatment were analyzed by flow cytometry. First, cells were pretreated with ZVAD-fmk to block TRAIL-induced apoptosis. The respective binding sites of rhTRAIL and primary antibodies to DR4/DR5 are different, which obviates the undetectability of TRAIL-occupied DR4/DR5. (B) A graphical representation of the mean ( \pm SD) data presented in (A). All assays were repeated at least three times. Columns, data; bar, SD; $\mathrm{P}<0.05$ compared with control.

is no direct correlation between the expression level of a death receptor and the sensitivity of cancer cells to TRAIL again. However, after $50 \mathrm{ng} / \mathrm{ml}$ rhTR AIL treatment, parental H460 cells showed a progressive increase of DR4 and DR5 cell surface expression in a time dependent manner (Fig. 5), but the accumulation of death receptors on cell surface in acquired TRAIL-resistant H460R cells was very slight. In view of the unaltered mRNA and protein expression of death 
$\mathbf{A}$

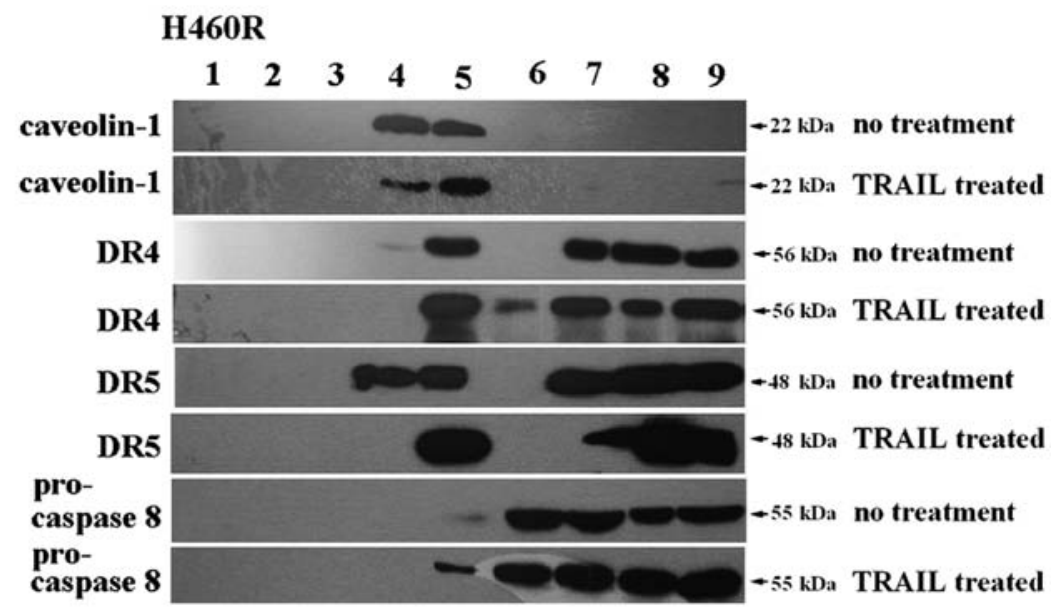

B
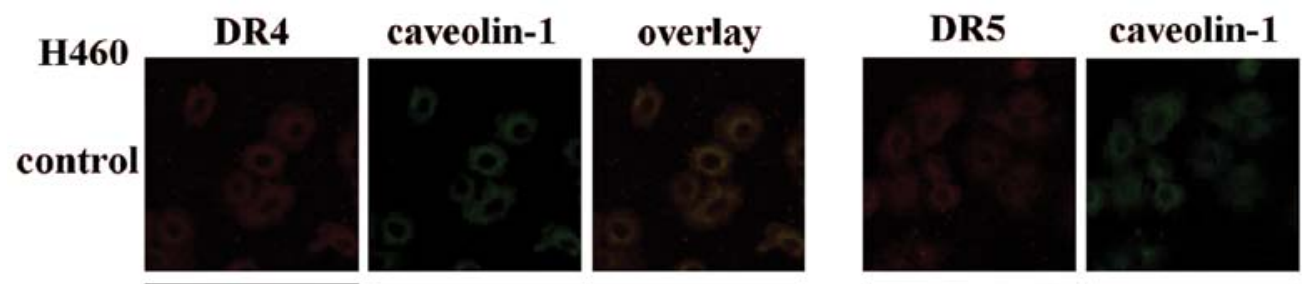

overlay
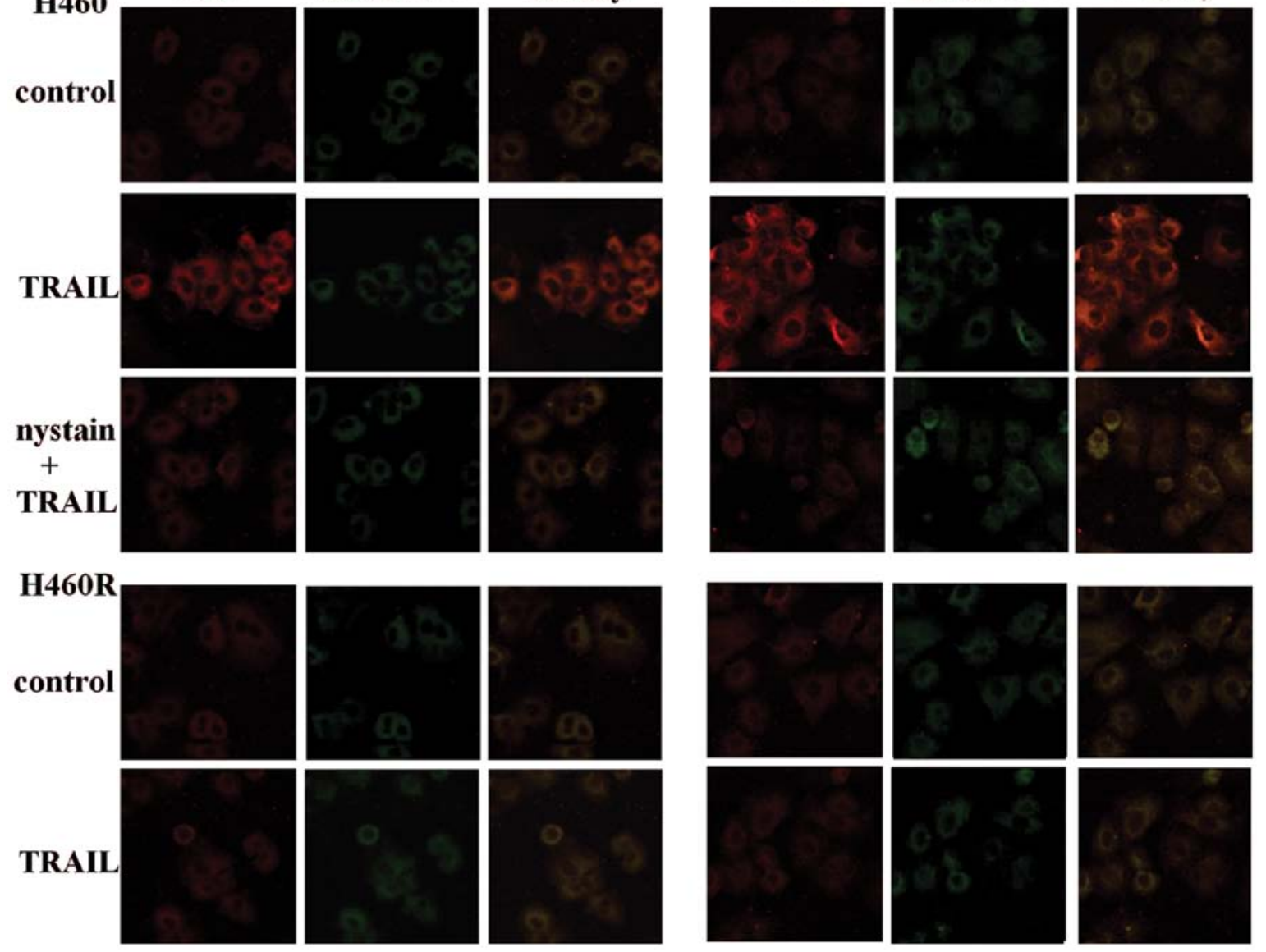

Figure 6. The localization and redistribution of death receptors in lipid rafts induced by TRAIL. (A) H460R cells with or without $50 \mathrm{ng} / \mathrm{ml} \mathrm{rhTRAIL}$ treatment were subjected to ultracentrifugation onto a linear sucrose gradient and cell fractions were isolated. Arabic numerals represent fractions of $1 \mathrm{ml}$ collected from the top to the bottom of the gradient. Lipid raft fractions 4 and 5 were identified by western blot analysis by using lipid raft marker caveolin-1. The protein expression of DR4, DR5, pro-caspase-8 in lipid raft and non-raft fractions were analyzed by western blot analysis. (B) H460/H460R cells with or without $50 \mathrm{ng} / \mathrm{ml} \mathrm{rhTRAIL}$ and/or nystatin treatment were counterstained with DR4/DR5 antibody and caveolin-1 antibody, after which immunofluorescence was analyzed by confocal microscopy. Caveolin-1 is a marker of lipid rafts. Actual magnification of all photomicrographs is $\mathrm{x} 400$.

receptors after TRAIL treatment, it is possible that the lack of death receptor accumulation on the cell surface contributes to development of acquired resistance to TRAIL in H460R cells.
TRAIL promotes death receptor aggregation in lipid rafts. Recent studies have highlighted the role of lipid rafts in the initiation of death receptor-induced apoptosis. We therefore investigated whether TRAIL sensitivity arises from 
A
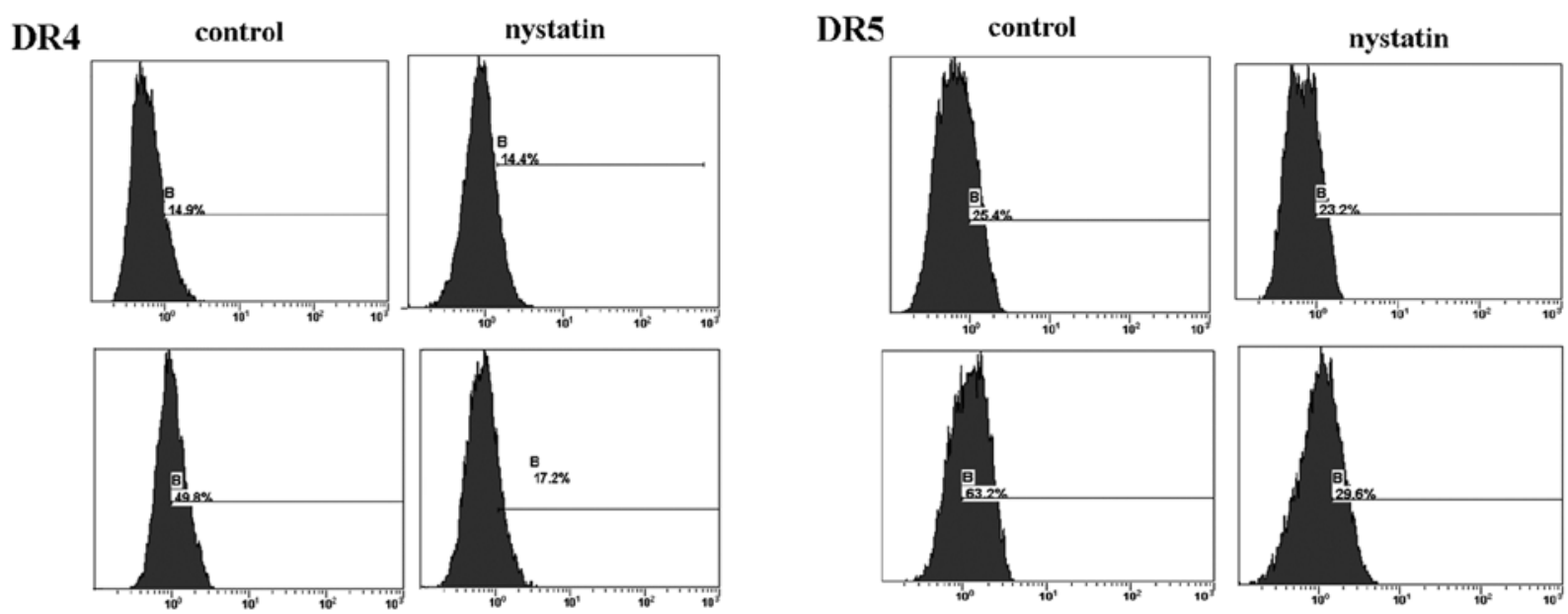

B

TRAIL nystatin+TRAIL

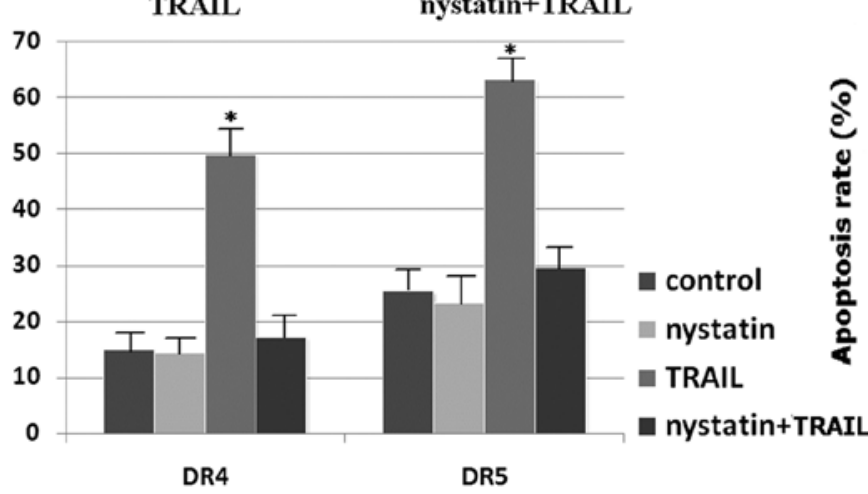

C

C TRAIL nystatin+TRAIL

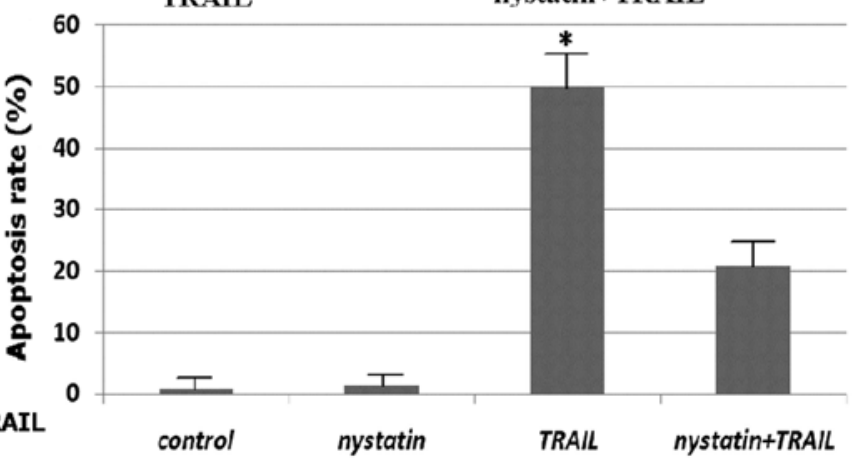

Figure 7. The localization and redistribution of death receptors in H460 cells with nystatin pretreatment. (A) The cell surface expression levels of DR4 and DR5 on $\mathrm{H} 460$ cells with $50 \mathrm{ng} / \mathrm{ml}$ nystatin pretreatment and 0 or $50 \mathrm{ng} / \mathrm{ml}$ rhTRAIL were analyzed by flow cytometry. First, cells were pretreated with ZVAD-fmk to block TRAIL-induced apoptosis. The respective binding sites of rhTRAIL and primary antibodies to DR4/DR5 are different, which obviates the undetectability of TRAIL-occupied DR4/DR5. (B) A graphical representation of the mean $( \pm \mathrm{SD})$ data presented in (A). All assays were repeated at least three times. Columns, data; bar, SD; "P<0.05 compared with control. (C) The apoptosis of $\mathrm{H} 460$ cells with $50 \mathrm{ng} / \mathrm{ml}$ nystatin and/or $50 \mathrm{ng} / \mathrm{ml}$ rhTRAIL treatment was analyzed by flow cytometry. At first, cells were pretreated with the caspase inhibitor ZVAD-fmk for $2 \mathrm{~h}$ to block endogenous TRAIL-induced apoptosis. All assays were repeated at least three times. The result was shown as histogram (mean $\pm \mathrm{SD}$ ). Columns, data; bar, $\mathrm{SD}$; ${ }^{\mathrm{P}}<0.05$ compared with control.

TRAIL-induced death receptor relocation to lipid rafts. In this study, upon ultracentrifugation of extracts from H460R cell line on a linear sucrose gradient, lipid raft marker caveolin-1 (26) was detected in fractions 4 and 5 (Fig. 6A). Combined with the corresponding results of $\mathrm{H} 460$ cell line in our previous study (28), it is shown that DR4 and DR5 were detected in both the lipid raft and non-raft fractions of both cell lines without rhTRAIL pretreatment, whereas pro-caspase- 8 was found in non-raft fractions only (Fig. 6A) (28). The results suggested that there was no correlation between TRAIL sensitivity and DR4/DR5 initial distribution in lipid rafts without any treatment of the cell lines. However, H460 cells pretreated with rhTRAIL showed a redistribution of DR4, DR5 and pro-caspase- 8 from the non-raft into the lipid raft fractions (28), which did not occur in H460R cells (Fig. 6A). The observations of $\mathrm{H} 460$ cells in our previous study is about intrinsic TRAIL-resistance by comparing with A549 (28). But in this study, combined with the observations of H460R cells, it suggested that the failure of TRAIL-induced death receptor redistribution into lipid rafts contributes to the development of acquired resistance to TRAIL in H460R cells and the migration of pro-caspase- 8 may be related to the formation of DISC in lipid rafts.

In order to confirm the above results, we examined DR4 and DR5 localization in H460 and H460R cells by confocal microscopy. Caveolin-1 was visualized with FITC-conjugated antibodies and DR4/DR5 were visualized with TRITC-conjugated antibodies. In TRAIL-sensitive H460 cells, TRAIL significantly promoted the colocalization of DR4/DR5 patches with caveolin-1 (Fig. 6B), whereas acquired TRAIL-resistant H460R cells exposed to rhTRAIL did not induce obvious DR4 or DR5 clustering (Fig. 6B). Taken together, our results indicate that death receptors do not redistribute into lipid rafts in H460R cells, possibly resulting in acquired TRAIL-resistance.

Nystatin prevents death receptor aggregation in lipid rafts. Nystatin, a cholesterol-sequestering agent that disrupts lipid rafts was used to investigate the effect of death receptor redistribution on apoptosis. A total of $50 \mathrm{ng} / \mathrm{ml}$ nystatin pretreatment of $\mathrm{H} 460$ cells for the last $1 \mathrm{~h}$ did not affect the initial distribution of DR4 and DR5 on the membrane 


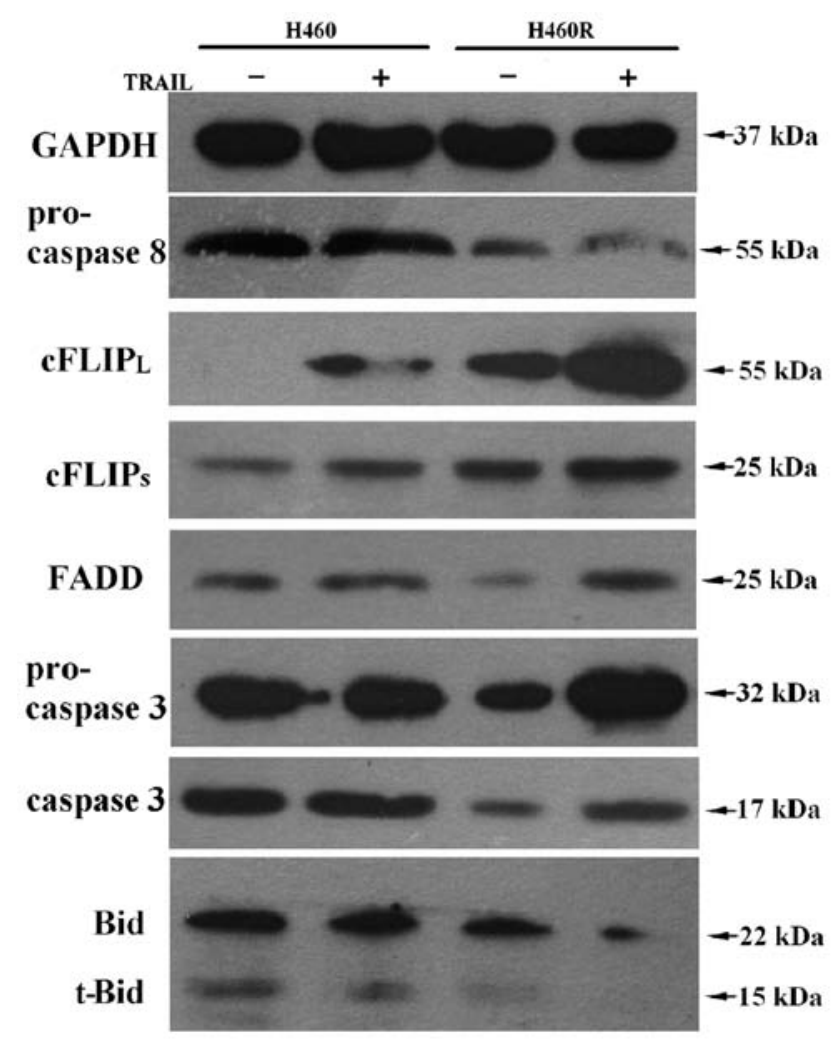

Figure 8. The distinct expression of apoptotic molecules of H460 and H460R cells with or without $50 \mathrm{ng} / \mathrm{ml}$ rhTRAIL treatment. The protein expression of apoptotic molecules from H460 and H460R cells were detected by western blot analysis. The protein expression was normalized with GAPDH.

surface (Fig. 7A and B) or in lipid rafts (see our previous results in reference 28 ), and the combination of nystatin and rhTRAIL did not induce obvious DR4 or DR5 clustering on the membrane surface (Fig. 7A and B) or in lipid rafts (Fig. 6B) (28). Similar observations were made for procaspase-8 (28). Nystatin treatment significantly suppressed TRAIL-induced apoptosis (Fig. 7C). Similar results of H460 cells were also observed in our previous study on intrinsic TRAIL-resistance by comparing with A549 and H460 cells (28). Taken together, our results suggest that TRAIL-induced DR4 and DR5 clustering in aggregated lipid rafts facilitates TRAIL-sensitive apoptosis in H460 cells, which confirms our above conclusion.

The distinct expression of apoptotic molecules. We also determined the expression of some apoptotic molecules by western blot analysis (Fig. 8). Pro-caspase-8, FADD, pro-caspase-3, caspase-3 and Bid or truncated Bid showed higher expression levels in H460 cells, whereas cFLIP showed higher expression level in H460R cells. The result suggest that $\mathrm{H} 460$ cells possess a higher activity of apoptosis not only in a receptor-mediated extrinsic pathway, but also in an intrinsic pathway involving mitochondria.

\section{Discussion}

Resistance to TRAIL is a major limitation for its clinical use in the treatment of human cancers. TRAIL-resistance may be intrinsic or acquired during a course of therapy. Intrinsic resistance is observed when tumors are first exposed to TRAIL, whereas acquired resistance is seen in tumors that no longer respond to TRAIL to which they were initially sensitive. The molecular alterations leading to TRAIL-resistance have been mostly studied in the context of cell lines that are intrinsically resistant to TRAIL. However, little is known about the molecular alterations that contribute to the development of acquired resistance during treatment with TRAIL. Understanding the basis of the acquired resistance of cancer cells to TRAIL-mediated apoptosis is obviously important as TRAIL may be used for the treatment of human cancers. To address the possible mechanisms of acquired TRAIL-resistance in lung cancer cell lines, we established an isogenic acquired TRAIL-resistant cell line and identified a new mechanism by which cancer cells can develop TRAIL-resistance.

Cisplatin is an irreplaceable drug of currently prevailing platinum-based regimens for the treatment of NSCLC. It is widely accepted that cisplatin causes cross-linking in intrastrands and interstrands of DNA, ultimately leading to cell death (29). We have shown that H460R cells are resistant to TRAIL but remain sensitive to chemotherapeutic agents, such as cisplatin (Fig. 1E), most likely because the apoptotic pathway induced by TRAIL is different from that induced by cisplatin. TRAIL-induced apoptosis is caspase-dependent, whereas cisplatin-induced DNA damage activates several pathways that may be caspase-independent. For example, activation of the mitogen activated protein kinase-extracellular signal-regulated kinase pathway facilitates apoptosis independently of caspases (29). Consequently, a patient with a tumor which has acquired resistance to TRAIL may still benefit from the management of platinum-based chemotherapeutic regimens and vice versa.

TRAIL-induced apoptosis occurs through its binding to its receptors DR4 and DR5 (27). In addition to DR4 and DR5, TRAIL interacts with two other receptors, decoy receptor 1 (DcR1/TRAIL-R3/TRID) and DcR2 (TRAIL-R4). DcR1 lacks a cytoplasmic death domain and DcR2 has a truncated death domain and they therefore inhibit TRAIL-induced apoptosis by competing with DR4 and DR5 for binding to TRAIL $(30,31)$. This is also considered to be the reason why normal cells escape TRAIL-induced apoptosis. However, many reports have indicated that the expression of decoy receptors does not correlate with resistance to TRAIL of cancer cell lines $(24,32,33)$. Consequently, we did not detect the expression of decoy receptors (DcR1 and DcR2) in this study.

In our study, analysis of mRNA and total protein expression of death receptors did not provide any explanation for acquired TRAIL-resistance in H460R cells (Fig. 2). Several recent studies suggest that the $\mathrm{mRNA}$ and protein expression of death receptors does not reflect their functional protein levels due to post-translational regulation. For example, O-glycosylation of death receptors correlates with TRAIL sensitivity in pancreatic carcinoma, non-small cell lung carcinoma and melanoma cell lines. Unfortunately, this is only found in a small portion of cancers (16). To further explore the role of death receptors in TRAIL-induced apoptosis, DR4/DR5 overexpression or silencing was performed in parental H460 cells and acquired TRAIL-resistant H460R 
cells. We showed that the overexpression of death receptors could overcome the resistance of H460R cells (Fig. 3) and that the silencing of death receptors could lead to resistance of H460 cells to TRAIL (Fig. 4). These results suggest that the expression of DR4/DR5 is necessary but not sufficient for TRAIL-induced apoptosis.

The effects of receptors appear to be upstream events during apoptosis initiation, and only cell membrane surface DR4 and DR5 are able to bind with TRAIL and transduce the apoptotic signal. It is reported that the functional status of death receptors correlates with death receptor expression levels on the cell surface in some colon cancer cells (19) and leukemia cells (20). In our previous study, SW480 and Hep-2R cell lines upregulated their sensitivity to TRAIL by elevating the cell surface expression of death receptors (17). The lack of expression of DR4 and DR5 on the surface of some cancer cells is therefore a resistance mechanism (34), regardless of total DR4 and DR5 protein levels. Absence of DR4/DR5 on the cell surface is sufficient to account for the failure to form DISC and undergo later events of apoptosis. In this study, without any treatment, the expression level of DR4/DR5 on the H460R cell surface is identical to that of the parental line H460, which seems contradictory to the view above. But the expression level of DR4/DR5 on the H460 cell surface is elevated by TRAIL treatment in a time-dependent manner (Fig. 5). At the same time, it is worth noting that the mRNA and total protein expression level of DR4/DR5 could not be affected by TRAIL (Fig. 2). Taken together, it suggested that the death receptors could migrate onto the cell surface in H460 cells but not in H460R cells after TRAIL treatment. Accordingly, the failure of death receptors to translocate to the cell surface is likely to contribute to the development of acquired resistance to TRAIL in H460R cells.

From the above we can come to the conclusion that death receptor redistribution to the cell surface is an important process for TRAIL-mediated apoptosis. Lipid rafts serve as plasma membrane platforms for death receptor redistribution and death receptor-initiated signals $(26,35,36)$. Several models for signal initiation in rafts have been proposed $(37,38)$. Redistribution of receptors in lipid rafts is related to the sensitivity of their respective ligands by regulating the efficacy of signaling (24). TRAIL also is capable of inducing DR4 and DR5 migration into lipid rafts as well as the formation of DISC (28) and agents can sensitize cells to TRAIL by upregulating the death receptors in lipid rafts, such as oxaliplatin (39), resveratrol (26), depsipeptide (25), and quercetin (36). Consistent with these reports, when compared with parental H460 cells, acquired TRAIL-resistant H460R cells display a decreased TRAILinduced DR4/DR5 relocation to lipid rafts, demonstrated in this study by western blot analysis of lipid isolation (Fig. 6A) (28) and confocal microscopy (Fig. 6B). Besides DR4 and DR5, pro-caspase- 8 is also recruited into lipid rafts in $\mathrm{H} 460$ cells (28).

Nystatin, a cholesterol-sequestering agent that disrupts lipid rafts was used in our studies to investigate the effect of lipid raft aggregation on apoptosis. Nystatin partially prevented lipid raft aggregation and DR4 and DR5 clustering (Figs. 6B and 7), and reduced apoptosis in parental H460 cells (Fig. 7). Similar observations were also found in our previous study about intrinsic TRAIL-resistance by comparing with A549 and H460 cells (28). These data suggest that the integrity of lipid rafts is necessary for death receptor clustering and that the difference in DR4/DR5-redistribution upon TRAIL treatment might explain the acquired TRAIL-resistance in H460R cells. However, the molecular mechanisms of death receptor redistribution in lipid rafts remained unclear. It may involve the protein sorting machinery. Recent studies suggest that protein transport and endocytosis pathways might play important roles in the regulation of cell surface death receptor expression $(19,40,41)$. Several studies have shown that the ubiquitin ligases $\mathrm{c}-\mathrm{Cbl}$ and $\mathrm{Cblb}$ are negative regulators of lipid rafts $(39,42,43)$. Others have reported that clathrin is a key component in the endocytosis pathways (44-46). Additional studies are required to characterize the signaling pathways that are responsible for TRAIL-induced redistribution of its death receptors and pro-caspase- 8 .

TRAIL is able to trigger the redistribution of death receptors as well as pro-caspase-8 into lipid rafts. This relocation in lipid rafts can subsequently induce the formation of a functional DISC. In the DISC, pro-caspase- 8 is cleaved and initiates TRAIL-induced apoptosis. Consequently, more death receptor and pro-caspase- 8 aggregation in lipid rafts of H460 cells might lead to higher expression levels of FADD, caspase-3 and Bid. Otherwise, acquired TRAIL-resistant H460R cells showed a higher expression of cFLIP in DISC (Fig. 8). cFLIP is a competitive inhibitor of caspase-8, blocks TRAIL-induced apoptosis by being recruited to the DISC and inhibiting of pro-caspase- 8 cleavage and activation, thereby preventing activation of the caspase cascade (47). Our results seemed not to rule out the possibility of cFLIP overexpression resulting in TRAIL-resistance, but compared with the event of TRAIL binding to its death receptors, the expression of cFLIP is a downstream event during caspase activation in isogenic H460R and H460 cells, so the translocation of death receptor into lipid rafts remains crucial in initialing apoptosis. An alternative explanation was also provided where more c-FLIP and RIP mediate the unfunctional DISCs assembly in the non-raft phase of the plasma membrane in TRAIL-resistant cancer cells, leading to the inhibition of pro-caspase- 8 cleavage and TRAIL-resistance (26). Our results are in line with the view that the expression levels of pro-caspase-8, FADD, and cFLIP are closely correlated with the status of death receptor redistribution into lipid rafts. Additional and further studies are required to confirm the views above. In addition to this, we also found that the expression level of Bid, which acts as a bridge between death receptor signaling and mitochondria signaling $(9,48)$, was also correlated with the redistribution of death receptors.

In conclusion, our studies indicate that TRAIL does not increase the total expression levels of death receptors but induces their redistribution into lipid rafts in TRAIL-sensitive H460 cells, and that death receptors must be properly expressed on the cell surface to recruit the components of DISC into lipid rafts before transmitting an apoptotic signal from their ligands, and that the development of acquired TRAIL-resistance is caused, at least in part, by the absence of TRAIL-induced redistribution of death receptors ino lipid rafts. Targeting the molecular mechanism which modulates death receptor relocation to lipid rafts may generate novel therapeutic strategies in overcoming TRAIL-resistance and 
thus provide an effective therapeutic approach in TRAILbased combination treatments of NSCLC and possibly in other human cancers.

\section{Acknowledgements}

This study was supported by grants from National Natural Science Foundation of China (no. 81071908).

\section{References}

1. Wiley SR, Schooley K, Smolak PJ, Din WS, Huang CP, Nicholl JK, Sutherland GR, Smith TD, Rauch C, Smith CA, et al: Identification and characterization of a new member of the TNF family that induces apoptosis. Immunity 3: 673-682, 1995.

2. Pitti RM, Marsters SA, Ruppert S, Donahue CJ, Moore A and Ashkenazi A: Induction of apoptosis by Apo-2 ligand, a new member of the tumor necrosis factor cytokine family. J Biol Chem 271: 12687-12690, 1996

3. Ichikawa K, Liu W, Zhao L, Wang Z, Liu D, Ohtsuka T, Zhang H, Mountz JD, Koopman WJ, Kimberly RP and Zhou T: Tumoricidal activity of a novel anti-human DR5 monoclonal antibody without hepatocyte cytotoxicity. Nat Med 7: 954-960, 2001.

4. Hao C, Song JH, Hsi B, Lewis J, Song DK, Petruk KC, Tyrrell DL and Kneteman NM: TRAIL inhibits tumor growth but is nontoxic to human hepatocytes in chimeric mice. Cancer Res 64: 8502-8506, 2004.

5. Gajewski TF: On the TRAIL toward death receptor-based cancer therapeutics. J Clin Oncol 25: 1305-1307, 2007.

6. Pan G, O'Rourke K, Chinnaiyan AM, Gentz R, Ebner R, Ni J and Dixit VM: The receptor for the cytotoxic ligand TRAIL. Science 276: 111-113, 1997.

7. Pan G, Ni J, Wei YF, Yu G, Gentz R and Dixit VM: An antagonist decoy receptor and a death domain-containing receptor for TRAIL. Science 277: 815-818, 1997.

8. Johnstone RW, Frew AJ and Smyth MJ: The TRAIL apoptotic pathway in cancer onset, progression and therapy. Nat Rev Cancer 8: 782-798, 2008

9. Luo X, Budihardjo I, Zou H, Slaughter C and Wang X: Bid, a $\mathrm{Bcl} 2$ interacting protein, mediates cytochrome c release from mitochondria in response to activation of cell surface death receptors. Cell 94: 481-490, 1998.

10. Ivanov VN, Bhoumik A and Ronai Z: Death receptors and melanoma resistance to apoptosis. Oncogene 22: 3152-3161, 2003.

11. Lane D, Cote M, Grondin R, Couture MC and Piche A: Acquired resistance to TRAIL-induced apoptosis in human ovarian cancer cells is conferred by increased turnover of mature caspase-3. Mol Cancer Ther 5: 509-521, 2006.

12. Lee TJ, Lee JT, Park JW and Kwon TK: Acquired TRAIL resistance in human breast cancer cells are caused by the sustained cFLIP(L) and XIAP protein levels and ERK activation. Biochem Biophys Res Commun 351: 1024-1030, 2006.

13. Wang X, Chen W, Zeng W, Bai L, Tesfaigzi Y, Belinsky SA and Lin Y: Akt-mediated eminent expression of c-FLIP and Mcl-1 confers acquired resistanceto TRAIL-induced cytotoxicity to lung cancer cells. Mol Cancer Ther 7: 1156-1163, 2008.

14. Zhang Land and Fang B: Mechanisms of resistance to TRAIL-induced apoptosis in cancer. Cancer Gene Ther 12: 228-237, 2005 .

15. Jonsson G, Paulie S and Grandien A: High level of cFLIP correlates with resistance to death receptor-induced apoptosis in bladder carcinoma cells. Anticancer Res 23: 1213-1218, 2003.

16. Wagner KW, Punnoose EA, Januario T, Lawrence DA, Pitti RM, Lancaster K, Lee D, von Goetz M, Yee SF, Totpal K, Huw L, Katta V, Cavet G, Hymowitz SG, Amler L and Ashkenazi A: Death-receptor O-glycosylation controls tumor-cell sensitivity to the proapoptotic ligand Apo2L/TRAIL. Nat Med 13: 1070-1077, 2007.

17. Wu F, Hu Y, Long J, Zhou YJ, Zhong YH, Liao ZK, Liu SQ, Zhou FX, Zhou YF and Xie CH: Cytotoxicity and radiosensitization effect of TRA-8 on radioresistant human larynx squamous carcinoma cells. Oncol Rep 21: 461-465, 2009.
18. Griffith TS, Rauch CT, Smolak PJ, Waugh JY, Boiani N, Lynch DH, Smith CA, Goodwin RG and Kubin MZ: Functional analysis of TRAIL receptors using monoclonal antibodies. J Immunol 162: 2597-2605, 1999.

19. Jin Z, McDonald ER III, Dicker DT and El-Deiry WS: Deficient tumor necrosis factor-related apoptosis-inducing ligand (TRAIL) death receptor transport to the cell surface in human colon cancer cells selected for resistance to TRAIL-induced apoptosis. J Biol Chem 279: 35829-35839, 2004

20. Cheng J, Hylander BL, Baer MR, Chen X and Repasky EA: Multiple mechanisms underlie resistance of leukemia cells to Apo2 Ligand/TRAIL. Mol Cancer Ther 5: 1844-1853, 2006.

21. Simons Kand and Vaz WL: Model systems, lipid rafts, and cell membranes. Annu Rev Biophys Biomol Struct 33: 269-295, 2004.

22. Cummins JM, Kohli M, Rago C, Kinzler KW, Vogelstein B and Bunz F: X-linked inhibitor of apoptosis protein (XIAP) is a nonredundant modulator of tumor necrosis factor-related apoptosis-inducing ligand (TRAIL)-mediated apoptosis in human cancer cells. Cancer Res 64: 3006-3008, 2004.

23. Soderstrom TS, Poukkula M, Holmstrom TH, Heiskanen KM and Eriksson JE: Mitogen-activated protein kinase/extracellular signal-regulated kinase signaling in activated $\mathrm{T}$ cells abrogates TRAIL-induced apoptosis upstream of the mitochondrial amplification loop and caspase-8. J Immunol 169: 2851-2860, 2002.

24. Song JH, Tse MC, Bellail A, Phuphanich S, Khuri F, Kneteman NM and Hao C: Lipid rafts and nonrafts mediate tumor necrosis factor related apoptosis-inducing ligand induced apoptotic and nonapoptotic signals in non small cell lung carcinoma cells. Cancer Res 67: 6946-6955, 2007.

25. Vanoosten RL, Moore JM, Ludwig AT and Griffith TS: Depsipeptide (FR901228) enhances the cytotoxic activity of TRAIL by redistributing TRAIL receptor to membrane lipid rafts. Mol Ther 11: 542-552, 2005.

26. Delmas D, Rebe C, Micheau O, Athias A, Gambert P, Grazide S, Laurent G, Latruffe N and Solary E: Redistribution of CD95, DR4 and DR5 in rafts accounts for the synergistic toxicity of resveratrol and death receptor ligands in colon carcinoma cells. Oncogene 23: 8979-8986, 2004.

27. Hao C, Song JH, Vilimanovich $U$ and Kneteman NM: Modulation of TRAIL signaling complex. Vitam Horm 67: 81-99, 2004.

28. Ouyang W, Yang C, Liu Y, Xiong J, Zhang J, Zhong Y, Zhang G, Zhou F, Zhou Y and Xie C: Redistribution of DR4 and DR5 in lipid rafts accounts for the sensitivity to TRAIL in NSCLC cells. Int J Oncol 39: 1577-1586, 2011.

29. Siddik ZH: Cisplatin: mode of cytotoxic action and molecular basis of resistance. Oncogene 22: 7265-7279, 2003.

30. Sheikh MS, Huang Y, Fernandez-Salas EA, El-Deiry WS, Friess H, Amundson S, Yin J, Meltzer SJ, Holbrook NJ and Fornace AJ Jr: The antiapoptotic decoy receptor TRID/TRAIL-R3 is a p53-regulated DNA damage-inducible gene that is overexpressed in primary tumors of the gastrointestinal tract. Oncogene 18: 4153-4159, 1999.

31. Liu X, Yue P, Khuri FR and Sun SY: Decoy receptor 2 (DcR2) is a p53 target gene and regulates chemosensitivity. Cancer Res 65: 9169-9175, 2005.

32. Zhang Yand and Zhang B: TRAIL resistance of breast cancer cells is associated with constitutive endocytosis of death receptors 4 and 5. Mol Cancer Res 6: 1861-1871, 2008.

33. Gomez-Benito M, Martinez-Lorenzo MJ, Anel A, Marzo I and Naval J: Membrane expression of DR4, DR5 and caspase-8 levels, but not Mcl-1, determine sensitivity of human myeloma cells to Apo2L/TRAIL. Exp Cell Res 313: 2378-2388, 2007.

34. Horak P, Pils D, Haller G, Pribill I, Roessler M, Tomek S, Horvat R, Zeillinger R, Zielinski C and Krainer M: Contribution of epigenetic silencing of tumor necrosis factor-related apoptosis inducing ligand receptor 1 (DR4) to TRAIL resistance and ovarian cancer. Mol Cancer Res 3: 335-343, 2005.

35. Muppidi JR, Tschopp J and Siegel RM: Life and death decisions: secondary complexes and lipid rafts in TNF receptor family signal transduction. Immunity 21: 461-465, 2004.

36. Psahoulia FH, Drosopoulos KG, Doubravska L, Andera L and Pintzas A: Quercetin enhances TRAIL-mediated apoptosis in colon cancer cells by inducing the accumulation of death receptors in lipid rafts. Mol Cancer Ther 6: 2591-2599, 2007.

37. Simons Kand and Toomre D: Lipid rafts and signal transduction. Nat Rev Mol Cell Biol 1: 31-39, 2000.

38. Dimanche-Boitrel MT, Meurette O, Rebillard A and Lacour S: Role of early plasma membrane events in chemotherapy-induced cell death. Drug Resist Updat 8: 5-14, 2005. 
39. Xu L, Qu X, Zhang Y, Hu X, Yang X, Hou K, Teng Y, Zhang J, Sada K and Liu Y: Oxaliplatin enhances TRAIL-induced apoptosis in gastric cancer cells by CBL-regulated death receptor redistribution in lipid rafts. FEBS Lett 583: 943-948, 2009.

40. Austin CD, Lawrence DA, Peden AA, Varfolomeev EE, Totpal K, De Maziere AM, Klumperman J, Arnott D, Pham V, Scheller RH and Ashkenazi A: Death-receptor activation halts clathrin-dependent endocytosis. Proc Natl Acad Sci USA 103: 10283-10288, 2006.

41. Ren YG, Wagner KW, Knee DA, Aza-Blanc P, Nasoff M and Deveraux QL: Differential regulation of the TRAIL death receptors DR4 and DR5 by the signal recognition particle. Mol Biol Cell 15: 5064-5074, 2004.

42. Hawash IY, Kesavan KP, Magee AI, Geahlen RL and Harrison ML: The Lck SH3 domain negatively regulates localization to lipid rafts through an interaction with $\mathrm{c}-\mathrm{Cbl}$. J Biol Chem 277: 5683-5691, 2002

43. Qu X, Miah SM, Hatani T, Okazaki M, Hori-Tamura N, Yamamura H, Hotta $\mathrm{H}$ and Sada K: Selective inhibition of Fcepsilon RI-mediated mast cell activation by a truncated variant of Cbl-b related to the rat model of type 1 diabetes mellitus. J Biochem 137: 711-720, 2005.
44. Lee KH, Feig C, Tchikov V, Schickel R, Hallas C, Schutze S, Peter ME and Chan AC: The role of receptor internalization in CD95 signaling. EMBO J 25: 1009-1023, 2006.

45. Schneider-Brachert W, Tchikov V, Neumeyer J, Jakob M, Winoto-Morbach S, Held-Feindt J, Heinrich M, Merkel O, Ehrenschwender M, Adam D, Mentlein R, Kabelitz D and Schutze S: Compartmentalization of TNF receptor 1 signaling: internalized TNF receptosomes as death signaling vesicles. Immunity 21: 415-428, 2004

46. Zhang Y, Yoshida T and Zhang B: TRAIL induces endocytosis of its death receptors in MDA-MB-231 breast cancer cells. Cancer Biol Ther 8: 917-922, 2009.

47. Nam SY, Jung GA, Hur GC, Chung HY, Kim WH, Seol DW and Lee BL: Upregulation of FLIP(S) by Akt, a possible inhibition mechanism of TRAIL-induced apoptosis in human gastric cancers. Cancer Sci 94: 1066-1073, 2003.

48. $\mathrm{Li} \mathrm{H}, \mathrm{Zhu} \mathrm{H}, \mathrm{Xu} \mathrm{CJ}$ and Yuan J: Cleavage of BID by caspase 8 mediates the mitochondrial damage in the Fas pathway of apoptosis. Cell 94: 491-501, 1998. 